\title{
PRODUTIVIDADE DE FORRAGEM E EFICIÊNCIA DE UTILIZAÇÃO DA RADIAÇÃO EM PASTAGENS DE Trachypogon plumosus NOS CERRADOS DE RORAIMA
}

\author{
COSTA, Newton de Lucena ${ }^{1}$ \\ MORAES, Anibal de ${ }^{2}$ \\ CARVALHO, Paulo César de Faccio ${ }^{3}$ \\ MONTEIRO, Alda Lúcia Gomes ${ }^{4}$ \\ SILVA, Ana Luisa Palhano ${ }^{5}$ \\ MAGALHÃES, João Avelar ${ }^{6}$ \\ OLIVEIRA, Ricardo Augusto de ${ }^{7}$
}

RESUMO: Nos cerrados de Roraima, as pastagens nativas representam o principal recurso forrageiro para a alimentação dos ruminantes e Trachypogon plumosus é a gramínea predominante nas áreas planas e não inundáveis. Neste trabalho avaliou-se o efeito da idade de rebrota $(21,28,35,42,49,56,63$ e 70 dias) sobre a produtividade de matéria seca (MS) e a eficiência de utilização da radiação (EUR) por Trachypogon plumosus, durante o período chuvoso, em condições de campo. O aumento da idade de rebrota resultou em maiores rendimentos de forragem, taxa absoluta de crescimento, taxa de crescimento da cultura, taxa de crescimento relativo e índice de área foliar. As relações entre idades de rebrota e os rendimento de MS, taxa absoluta de crescimento e EUR foram ajustadas ao modelo quadrático de regressão, sendo os máximos valores registrados aos 65,6 (1.152 kg ha $\left.{ }^{-1} \mathrm{de} \mathrm{MS}\right) ; 44,5(21,3 \mathrm{~kg}$ $\mathrm{ha}^{-1} \mathrm{dia}^{-1} \mathrm{de}$ MS $)$ e 42,7 dias de rebrota $\left(0,281 \mathrm{~g}\right.$ de $\mathrm{MS} / \mathrm{m}^{2} /$ dia.MJ), respectivamente. A resposta da produtividade de forragem à RFA incidente foi quadrática e o máximo valor estimado em $509,6 \mathrm{MJ} / \mathrm{m}^{2}$, o qual correspondeu a 1.169 $\mathrm{kg} \mathrm{ha}^{-1}$ de MS. O período mais adequado para a utilização da pastagem situa-se entre 42 e 49 dias de rebrota, pois concilia produtividade de forragem da gramínea com a maximização da EUR.

Palavras-chave: Planta-idade. Planta-folha. Matéria seca. Taxa de crescimento.

\section{FORAGE YIELD AND RADIATION USE EFFICIENCY OF Trachypogon plumosus PASTURES IN RORAIMA'S SAVANNAS}

\begin{abstract}
SUMMARY: In Roraima's savannas, native pastures are the main source for ruminant feed and Trachypogon plumosus is the predominant grass in plain and non-flood areas. The effects of regrowth plant age $(21,28,35,42,49$, 56, 63 and 70 days) on dry matter (DM) yield, and radiation use efficiency (RUE) of Trachypogon plumosus pastures, during rainy season, was evaluated under natural field conditions. DM yields, absolute growth rate (AGR), crop growth and relative growth rates and leaf area index increased consistently with plant regrowth age. The relationships between regrowth plant age, DM yield, absolute growth rate (AGR) and RUE adjusted to the quadratic regression model. The maximum DM yield, AGR and RUE were estimated at $65.6\left(1,152 \mathrm{~kg} \mathrm{ha}^{-1}\right.$ of DM); $44.5(21.3$ $\mathrm{kg} \mathrm{ha}^{-1} \mathrm{day}^{-1}$ of DM) and 42.7 regrowth days $(0.281 \mathrm{~g}$ of DM/m²/day.MJ), respectively. The response of forage yield to incident photosynthetically active radiation was quadratic and maximum value estimated at $509.6 \mathrm{MJ} / \mathrm{m}^{2}$, which corresponded to $1,169 \mathrm{~kg} \mathrm{ha}^{-1}$ of DM. These data suggest that cutting at 42 to 49 days were optimal for obtain maximum dry matter yields and improved the incident RUE.
\end{abstract}

\footnotetext{
${ }^{1}$ Eng $^{\mathrm{o}} \mathrm{Agr}^{\mathrm{o}}$, Dr., Pesquisador da Empresa Brasileira de Pesquisa Agropecuária/Centro de Pesquisa Agroflorestal de Roraima, Embrapa Roraima, Boa Vista, RR.

${ }^{2} \mathrm{Eng}^{\mathrm{o}} \mathrm{Agr}^{\circ}$, Dr., Professor Associado II, UFPR, Curitiba, PR.

${ }^{3}$ Zootecnista, Dr., Professor Adjunto, UFRGS, Porto Alegre, RS.

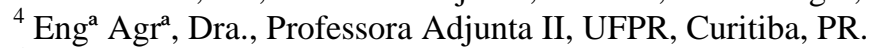

${ }^{5}$ Professora Universitária, Universidade Tuiuti, Curitiba, PR.

${ }^{6}$ Méd. Vet., Dr., Pesquisador da Empresa Brasileira de Pesquisa Agropecuária/Centro de Pesquisa Agropecuária do Meio-Norte, EMBRAPA/CPAMN/UEP de Parnaíba, Parnaíba, PI.

${ }^{7}$ Eng $^{\circ}$ Agr $^{\circ}$, Dr., Professor Adjunto, UFPR, Curitiba, PR.
} 
Keywords: Dry matter. Leaves. Plant age. Plant growth rates.

\section{INTRODUÇÃO}

Em Roraima, a pecuária bovina é uma das principais atividades econômicas e as pastagens nativas representam importante recurso forrageiro para alimentação dos rebanhos. No entanto, a utilização de práticas de manejo inadequadas, caracterizadas por altas pressões de pastejo e sistema contínuo de pastoreio contribuem para a obtenção de reduzidas produtividades de forragem, com reflexos negativos na composição química, capacidade de rebrota e persistência das pastagens (GIANLUPPI; GIANLUPPI; SMIDERLE, 2001; COSTA et al., 2014).

Nas áreas planas e não inundáveis dos cerrados, onde Trachypogon plumosus é a gramínea predominante, constituindo entre 80 e $90 \%$ da composição botânica das pastagens nativas, a produção animal pode ser muito baixa, sendo necessário entre 6 e 10 ha para a manutenção de um bovino adulto, o que inviabiliza economicamente a atividade pecuária, desde que não sejam implementadas práticas de manejo adequadas para o seu melhoramento (COSTA et al., 2011). A gramínea apresenta ciclo perene, hábito de crescimento cespitoso, folhas pilosas e plantas com 40 a $80 \mathrm{~cm}$ de altura. No entanto, são escassas as informações sobre o potencial produtivo e a resposta da gramínea às condições ambientais dos cerrados de Roraima, visando à proposição de práticas de manejo mais sustentáveis (COSTA et al., 2013).

Da energia incidente sobre a Terra, apenas $5 \%$, ao redor de $0,2 \mathrm{MJ} . \mathrm{m}^{2}$.dia é aproveitado pelas plantas para a formação de carboidratos. A radiação fotossinteticamente ativa (RFA), que compreende comprimentos de ondas entre 400 e $700 \mathrm{~nm}$, é a responsável pela fotossíntese e representa entre 45 e $50 \%$ da radiação solar incidente (BALDISSERA, 2010). A eficiência do uso da radiação depende da interação entre a vegetação e o ambiente, que define como os processos de fotossíntese e transpiração serão afetados pelos elementos climáticos e edáficos ou como a estrutura do dossel da pastagem influencia a quantidade de radiação incidente que atinge os seus diferentes estratos e sua absorção pelas plantas (SHEEHY; COOPER, 1973). A quantidade de energia disponível para a produção de biomassa de forragem varia com a latitude, hora do dia, estação do ano e nebulosidade (BONHOMME, 2000).

A relação entre a produção de MS e RFA interceptada ou absorvida tem sido utilizada para definir a eficiência de uso da radiação pelas culturas, a qual pode apresentar uma linearidade em condições bióticas e ambientais não limitantes (SHIBLES; WEBER, 1965, 1966; SIVAKUMAR; VIRMANI, 1984; BONHOMME, 2000; SCHÖFFEL; VOLPE, 2001; SILVA JÚNIOR et al., 2009), notadamente quando se considera a comunidade de plantas e não a folha isoladamente. Entretanto, nem sempre há aumento linear na produtividade de MS, em função da radiação interceptada, evidenciando que há outros fatores relacionados, como potencial genético, hábito de crescimento, arquitetura foliar, práticas de manejo da pastagem e disponibilidade de água e nutrientes (BALDISSERA, 2010).

$\mathrm{O}$ objetivo do trabalho foi avaliar se as idades de rebrota afetam a produtividade de forragem e a eficiência de utilização da radiação incidente em pastagens de Trachypogon plumosus.

\section{MATERIAL E MÉTODO}

O ensaio foi conduzido em pastagem nativa com predominância de T. plumosus, localizada em Boa Vista $\left(60^{\circ} 43^{\prime}\right.$ de longitude oeste e $2^{\circ} 45^{\prime}$ de latitude norte), durante o período de maio a julho de 2011 . O clima da região, segundo a classificação de Köppen, é Awi, caracterizado por períodos seco e chuvoso bem definidos, com aproximadamente seis meses cada. A precipitação anual é de $1.600 \mathrm{~mm}$, sendo que 
$80 \%$ ocorrem nos seis meses do período chuvoso. Os dados de precipitação e temperatura, durante o período experimental, foram coletados através de pluviômetro e termômetro instalados na área experimental (Tabela 1).

Tabela 1. Precipitação e temperaturas mínimas, máximas e médias registradas durante o período experimental. Boa Vista, Roraima. (Maio/julho 2011).

\begin{tabular}{c|c|ccc}
\hline \multirow{2}{*}{ Meses } & $\begin{array}{c}\text { Precipitação } \\
\text { (mm) }\end{array}$ & \multicolumn{3}{|c}{ Temperatura } \\
\cline { 3 - 5 } & 544,9 & Mínima & Máxima & Média \\
\hline Maio & 379,8 & 23,0 & 30,8 & 26,9 \\
Junho & 318,2 & 22,7 & 31,7 & 27,2 \\
Julho & 22,2 & 32,1 & 27,1 \\
\hline
\end{tabular}

Fonte: Estação Meteorológica da Embrapa Roraima, Boa Vista, Roraima

O solo da área experimental é um Latossolo Amarelo Distrófico, textura média, fase cerrado, com as seguintes características químicas, na profundidade de $0-20 \mathrm{~cm}: \mathrm{pH}_{\mathrm{H} 2 \mathrm{O}}=4,8 ; \mathrm{P}=1,8 \mathrm{mg} / \mathrm{kg} ; \mathrm{Ca}=0,25$ $\mathrm{cmol}_{\mathrm{c}} \cdot \mathrm{dm}^{-3} ; \mathrm{Mg}=0,65 \mathrm{cmol}_{\mathrm{c}} \cdot \mathrm{dm}^{-3} ; \mathrm{K}=0,01 \mathrm{cmol}_{\mathrm{c}} \cdot \mathrm{dm}^{-3} ; \mathrm{Al}=0,61 \mathrm{cmol}_{\mathrm{c}} \mathrm{dm}^{-3} ; \mathrm{H}+\mathrm{Al}=2,64 \mathrm{cmol}_{\mathrm{c}} \cdot \mathrm{dm}^{-3} ;$ $\mathrm{SB}=0,91 \mathrm{cmol}_{\mathrm{c}} \cdot \mathrm{dm}^{-3} ; \mathrm{V}(\%)=25,6$ e $\mathrm{m}(\%)=40$

O delineamento experimental foi inteiramente casualizado com três repetições, sendo os tratamentos constituídos por oito idades de corte $(21,28,35,42,49,56,63$ e 70 dias após o rebaixamento da pastagem a $10 \mathrm{~cm}$ acima do solo). $\mathrm{O}$ tamanho das parcelas foi de 2,0 x 2,0 m, sendo a área útil de 1,0 $\mathrm{m}^{2}$. Os parâmetros avaliados foram rendimento de matéria seca (MS), taxa absoluta de crescimento (TAC), taxa média de crescimento (TMC), taxa de crescimento relativo (TCR), índice de área foliar (IAF) e eficiência de utilização da RFA incidente (EUR). A TAC foi obtida dividindo-se o rendimento de MS, em cada idade de corte, pelo respectivo período de rebrota. A TMC foi obtida pela formula: $\mathrm{TMC}=\mathrm{P}_{2}$ $\mathrm{P}_{1} / \mathrm{T}_{2}-\mathrm{T}_{1}$; onde $\mathrm{P}_{1}$ e $\mathrm{P}_{2}$ representam a produtividade de MS de duas amostragens sucessivas e, $\mathrm{T}_{1}$ e $\mathrm{T}_{2} \mathrm{o}$ intervalo de tempo, em dias, transcorrido entre as amostragens. A TCR foi obtida pelo uso da expressão: $\mathrm{TCR}=\mathrm{LnP}_{2}-\mathrm{LnP}_{1} / \mathrm{T}_{2}-\mathrm{T}_{1}$; onde $\mathrm{LnP}_{1}$ e $\mathrm{LnP}_{2}$ são os valores de logaritmos da $\mathrm{MS}$ de duas amostragens sucessivas e, $\mathrm{T}_{1}$ e $\mathrm{T}_{2} \mathrm{o}$ intervalo de tempo, em dias, transcorrido entre as amostragens. Para o cálculo da área foliar, em cada idade de rebrota foram coletadas amostras de folhas verdes completamente expandidas, procurando-se obter uma área entre 200 e $300 \mathrm{~cm}^{2}$. As amostras foram digitalizadas e a área foliar estimada com o auxílio de planímetro ótico eletrônico. Posteriormente, as amostras foram levadas à estufa com ar forçado a $65^{\circ} \mathrm{C}$ até atingirem peso constante, obtendo-se a massa seca foliar. A área foliar específica (AFE) foi determinada através da relação entre a área de folhas verdes e a sua massa seca $\left(\mathrm{cm}^{2} / \mathrm{g}\right.$ massa seca foliar). O IAF foi determinado a partir do produto entre a massa seca de folhas verdes $\left(\mathrm{g} / \mathrm{m}^{2}\right)$ pela AFE. A EUR foi obtida relacionando-se o rendimento de MS com a RFA incidente acumulada em cada idade de rebrota. Os dados de radiação solar foram coletados na Estação Climatológica do Instituto Nacional de Meteorologia localizada em Boa Vista $\left(95 \mathrm{~m}\right.$ de altitude, $2^{\circ} 49^{\prime}$ de latitude norte e $60^{\circ} 40^{\prime}$ de longitude oeste). A RFA incidente acumulada foi de 159; 219; 268; 323; 374; 421; 489 e 561 $\mathrm{MJ} / \mathrm{m}^{2}$, respectivamente para $21,28,35,42,49,56,63$ e 70 dias de rebrota.

Os dados foram submetidos à análise de variância, regressão e correlação considerando o nível de significância de 5\% de probabilidade. Para se estimar a resposta dos parâmetros avaliados às idades de rebrota, a escolha dos modelos de regressão baseou-se na significância dos coeficientes linear e quadrático, por meio do teste " $\mathrm{t}$ ", de Student, ao nível de 5\% de probabilidade. 


\section{RESULTADO E DISCUSSÃO}

Os rendimentos de MS e as TAC foram significativamente $(\mathrm{P}<0,05)$ afetados pela idade de rebrota, sendo as relações quadráticas e os valores máximos estimados aos 65,6 (1.152 $\left.\mathrm{kg} \mathrm{ha}^{-1}\right)$ e 47,8 dias $(21,3 \mathrm{~kg}$ $\mathrm{ha}^{-1} \mathrm{dia}^{-1}$ ), respectivamente (Figuras 1 e 2). Estes valores são semelhantes aos reportados por Mochiutti et al. (2000) para T. plumosus nos cerrados do Amapá (1.124 e $1.417 \mathrm{~kg} \mathrm{ha}^{-1}$ de MS, respectivamente, para pastagens roçadas ou queimadas anualmente), contudo inferiores aos estimados por Mata et al. (1985), na Venezuela, para pastagens de Trachypogon spp., submetidas a diferentes frequências de desfolhação (1.654; 2.309 e $2.631 \mathrm{~kg} \mathrm{ha}^{-1}$ de MS, respectivamente para 28, 49 e 63 dias). Para Trachypogon vestitus, Rippstein et al. (2001) constataram maiores rendimentos de MS com cortes aos 49 (2.985 $\left.\mathrm{kg} \mathrm{ha}^{-1}\right)$ ou 56 dias (3.349 $\left.\mathrm{kg} \mathrm{ha}^{-1}\right)$, comparativamente a 42 dias $\left(2.207 \mathrm{~kg} \mathrm{ha}^{-1}\right)$.

As altas taxas de crescimento, durante os períodos iniciais de rebrota, representam um mecanismo de adaptação da gramínea, pois ao reduzir o tempo para que ocorra a máxima interceptação da radiação solar incidente, promove uma melhor utilização da água devido ao sombreamento mais rápido do solo, o que favorece sua competitividade intraespecífica, notadamente naquelas situações em que a umidade do solo possa ser um dos fatores abióticos limitantes (LEMAIRE; AGNUSDEI, 2000).

Figura 1. Rendimento de forragem de Trachypogon plumosus, em função da idade de rebrota.

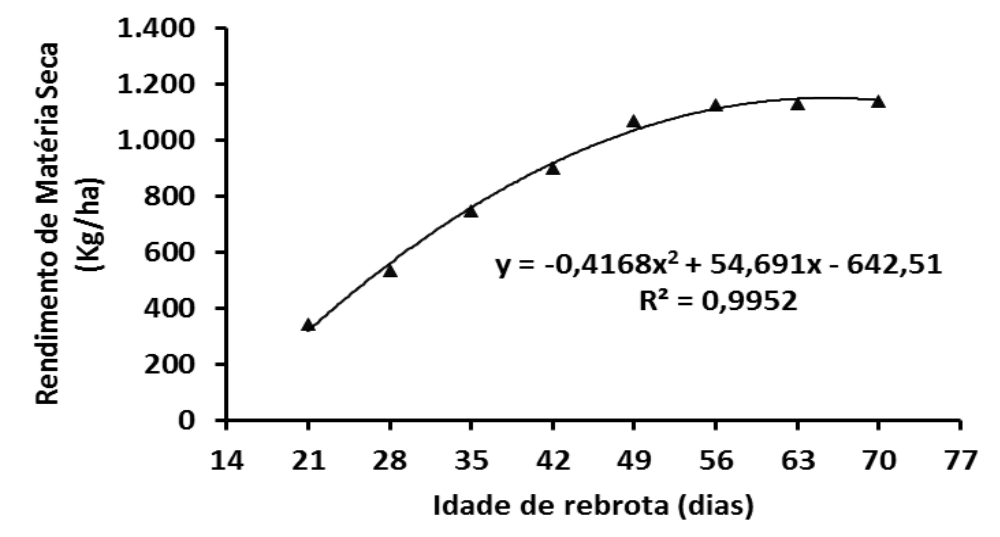

Fonte: Dados da pesquisa.

Os efeitos da idade de rebrota sobre a TMC e a TCR foram ajustados ao modelo exponencial (Figuras 2 e 3). Os maiores valores foram registrados no período entre $28\left(27,6 \mathrm{~kg} \mathrm{ha}^{-1} \mathrm{dia}^{-1} \mathrm{de}\right.$ MS e 0,0636 g.g dia $\left.{ }^{-1}\right)$ e 35 dias de rebrota $\left(30,5 \mathrm{~kg} \mathrm{ha}^{-1} \mathrm{dia}^{-1}\right.$ de MS e 0,0479 g.g. dia $\left.{ }^{-1}\right)$, os quais foram inferiores ao reportado por Tejos (2002) para pastagens de Trachypogon spp., submetidas a uma queima anualmente $\left(39,88 \mathrm{~kg} \mathrm{ha}^{-1} \mathrm{dia}^{-1}\right.$ de MS e 0,0541 g.g dia ${ }^{-1}$. No Rio Grande do Sul, Brum et al. (2008) reportaram TAC de 12,7 e 16,9 $\mathrm{kg} \mathrm{ha}^{-1} \mathrm{dia}^{-1}$ de MS, respectivamente para pastagens nativas submetidas à lotação contínua e rotativa, as quais foram inferiores às registradas neste trabalho. Em pastagens de Panicum maximum, Gomide et al. (2002) registraram relação linear positiva entre idade da planta e TCR $\left(0,055 ; 0,082\right.$ e 0,092 g.g dia ${ }^{-1}$, respectivamente para 7, 35 e 63 dias de rebrota). Parsons e Chapman (2000) sugerem como período mais adequado de utilização da pastagem aquele em que as TAC e as TMC são equivalentes, de modo a maximizar o acúmulo líquido de forragem e evitar as perdas por senescência que ocorrem a partir do momento em que as TAC são decrescentes e as variações na TMC são pequenas. 
Considerando-se esta premissa, no presente trabalho, o período entre 42 e 49 dias de rebrota seria o mais recomendado para a utilização de pastagens de $T$. plumosus, pois concilia a otimização entre a TAC e a TMC da gramínea, além de minimizar os efeitos decorrentes da senescência foliar.

Figura 2. Taxas absoluta e média de crescimento de Trachypogon plumosus, em função da idade de rebrota.

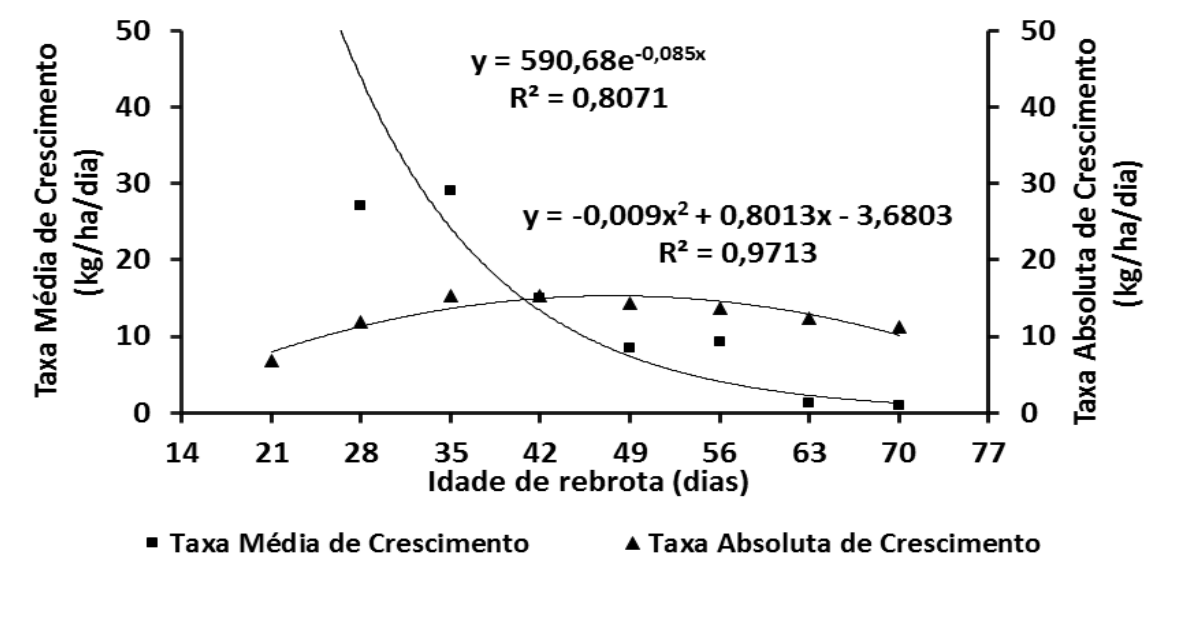

Fonte: Dados da pesquisa.

Figura 3. Taxa de crescimento relativo de Trachypogon plumosus, em função da idade de rebrota.

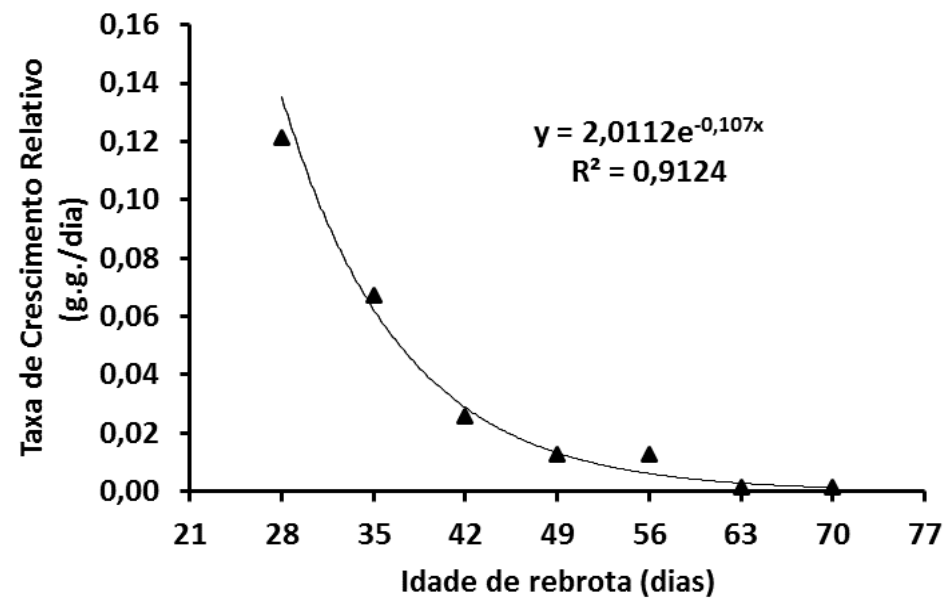

Fonte: Dados da pesquisa

O IAF foi proporcional às idades de rebrota, sendo a relação linear e positiva (Figura 4). Os valores obtidos foram superiores aos relatados por Baruch e Bilbao (1999) para T. plumosus $(1,31)$ e por Tejos (2002) para Axonopus purpusii (1,54), Hymenachne amplexicaulis $(1,02)$ e Panicum laxum $(0,72)$, gramíneas nativas dos cerrados da Venezuela. O IAF representa a síntese das características morfogênicas e estruturais da gramínea e reflete o balanço dos processos que determinam a oferta (fotossíntese) e a demanda (respiração, acúmulo de reservas, síntese e senescência de tecidos) de fotoassimilados, que estabelecem o ritmo de crescimento da pastagem (NABINGER; CARVALHO, 2009). 
Figura 4. Índice de área foliar de Trachypogon plumosus, em função da idade de rebrota.

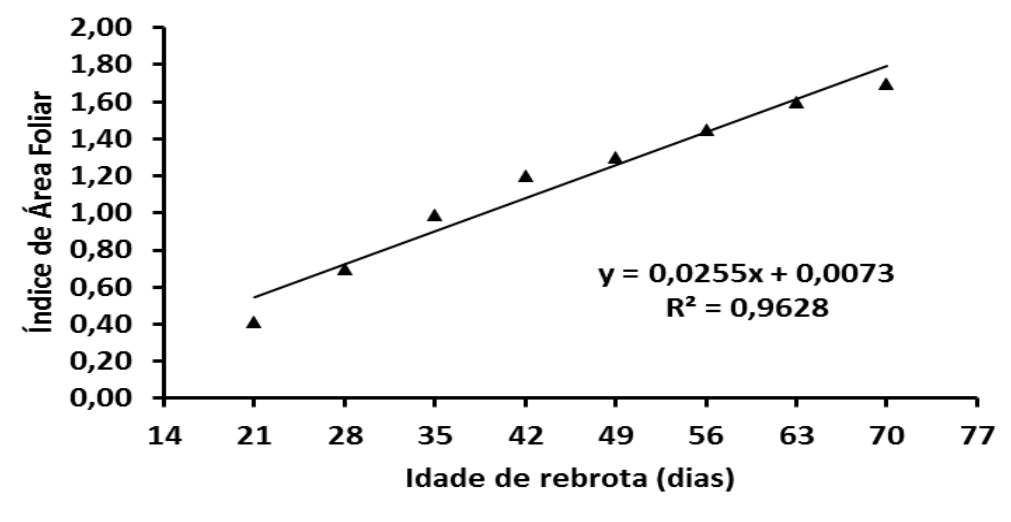

Fonte: Dados da pesquisa.

O IAF foi positivo e significativamente correlacionado com o rendimento de MS ( $\mathrm{r}=0,9638$; $\mathrm{p}=0,0019$ ). As gramíneas com maior habilidade competitiva desenvolvem arquitetura mais eficiente na interceptação de luz, através da rápida expansão de área foliar e colonização da camada superior do dossel, em decorrência do alongamento da bainha e entrenós do colmo (LEMAIRE, 2001; LEMAIRE et al., 2011). Pedreira e Pedreira (2007) reportaram que a produção de forragem depende mais de fatores que determinam a eficiência na interceptação da luz que a própria eficiência fotossintética. Após a completa expansão das folhas a fotossíntese decresce com a idade de rebrota como consequência do declínio do potencial metabólico e da mudança de posição relativa da folha dentro do dossel. Com 0 aumento do IAF, o potencial fotossintético das folhas, geralmente, diminui durante o transcorrer do período de rebrota, como consequência de seu envelhecimento (BARUCH et al., 1985; BORGES et al., 2011).

A resposta da produtividade de forragem à RFA incidente foi quadrática, sendo o máximo valor estimado em 509,6 MJ/m², o qual correspondeu a $1.169 \mathrm{~kg}$ de MS/ha (Figura 5). Em pastagens de azevém anual (Lolium multiflorum Lam.), Baldissera (2010) reportou relação linear entre produção de MS e RFA absorvida, a qual foi positivamente incrementada pela aplicação de doses de nitrogênio $(1.193 ; 3.216$; 4.105 e $6.408 \mathrm{~kg}$ de MS/ha, respectivamente para 0,50, 100 e $200 \mathrm{~kg}$ de N/ha). Respostas semelhantes foram constatadas por Barger et al. (2002) para pastagens de T. vestitus fertilizadas com nitrogênio e/ou fósforo.

Figura 5. Rendimento de matéria seca de Trachypogon plumosus, em função da radiação fotossinteticamente ativa (RFA) incidente.

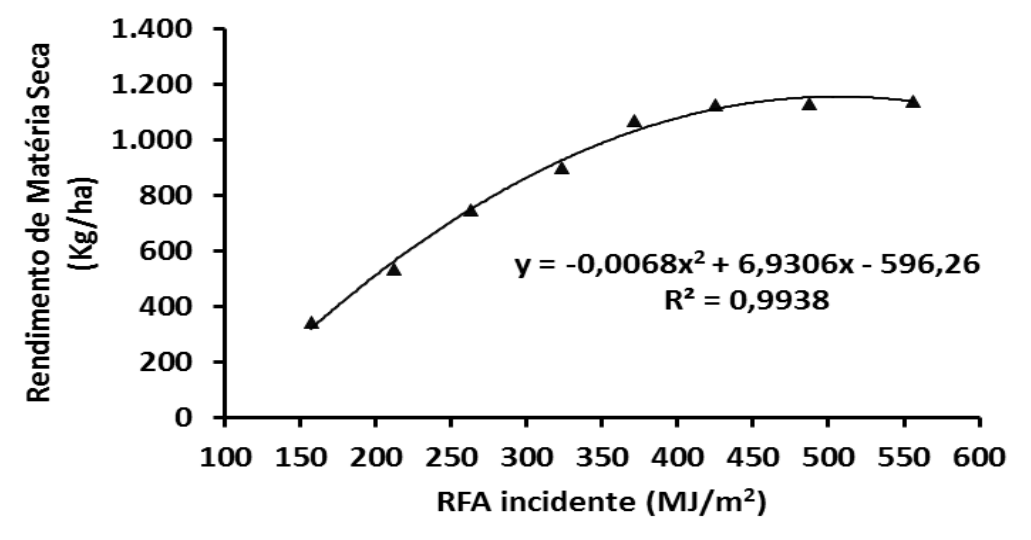

Fonte: Dados da pesquisa. 
O aumento linear no IAF da gramínea, em função das idades de rebrota, não apresentou correlação significativa com a EUR $(r=-0,046 ; p=0,1177)$, evidenciando o efeito de sombreamento das folhas superiores sobre as inseridas na porção basal da planta, as quais tem suas taxas de fotossíntese reduzidas, o que contribui para menores incrementos no acúmulo de forragem, apesar da elevada disponibilidade de RFA. No entanto, Baruch et al. (1985), Tejos (2002) e Baruch e Jackson (2005) reportaram relações lineares positivas entre IAF e RFA interceptada por T. vestitus, Hyparrhenia rufa e T. plumosus, respectivamente. Os valores para o IAF da gramínea foram inferiores aos recomendados por Humphreys (1991) como críticos para pastagens, normalmente entre 3 e 5, faixa em que ocorre a interceptação luminosa de cerca de 95\%. Baruch e Bilbao (1999) em pastagens de T. vestitus e Du et al. (2015) em lavouras de trigo (Triticum aestivum L.), constataram que a RFA interceptada e sua eficiência de utilização na produção de biomassa foi diretamente correlacionada com o IAF e inversamente proporcional ao coeficiente de extinção luminosa, condição que favoreceu a penetração de luz nos estratos inferiores das plantas e, consequentemente, maior fotossíntese líquida do dossel. Segundo Cooper (1983) as diferenças entre gramíneas forrageiras devem-se ao comprimento, largura e propriedades óticas da folha, ângulo de inserção entre a folha e o caule e rigidez das folhas que podem afetar sua estrutura e, por conseguinte, o IAF, a interceptação da radiação e o acúmulo de MS.

A eficiência de produção de MS, em função da RFA incidente, foi ajustada ao modelo quadrático de regressão (Figura 6). O máximo valor foi estimado aos 42,7 dias de rebrota $\left(0,281 \mathrm{~g}\right.$ de $\mathrm{MS} / \mathrm{m}^{2} / \mathrm{dia} . \mathrm{MJ}$ ), o qual foi inferior ao constatado por Fonseca et al. (2006) para gramíneas nativas do Rio Grande do Sul durante a primavera $\left(0,297 \mathrm{~g}\right.$ de $\mathrm{MS} / \mathrm{m}^{2} /$ dia.MJ $)$ e representou apenas $19 \%$ do estimado por Sivakumar e Virmani (1984) para pastagens de azevém fertilizadas com $150 \mathrm{~kg}$ de N/ha $\left(1,487 \mathrm{~g}\right.$ de $\left.\mathrm{MS} / \mathrm{m}^{2} / \mathrm{dia} . \mathrm{MJ}\right)$. Em pastagens de Axonopus aureus, Costa et al. (2011), durante o período seco, reportaram EUR de 0,341; 0,398 e 0,441 g de $\mathrm{MS} / \mathrm{m}^{2} /$ dia.MJ, respectivamente para plantas aos 35, 42 e 49 dias de rebrota. Estas discrepâncias evidenciam a possibilidade da melhoria das condições do ambiente de produção de pastagens de $T$. plumosus por meio da adoção de práticas de manejo que aumentem sua produtividade biológica primária, como por exemplo a utilização de fertilização, notadamente nitrogenada e fosfatada, visando maximizar os processos de absorção e conversão da RFA, considerando-se a baixa fertilidade natural dos solos sob vegetação de cerrados de Roraima.

Figura 6. Eficiência de utilização da radiação fotossinteticamente ativa incidente (RFAI), de folhas de Trachypogon plumosus, em função da idade de rebrota.

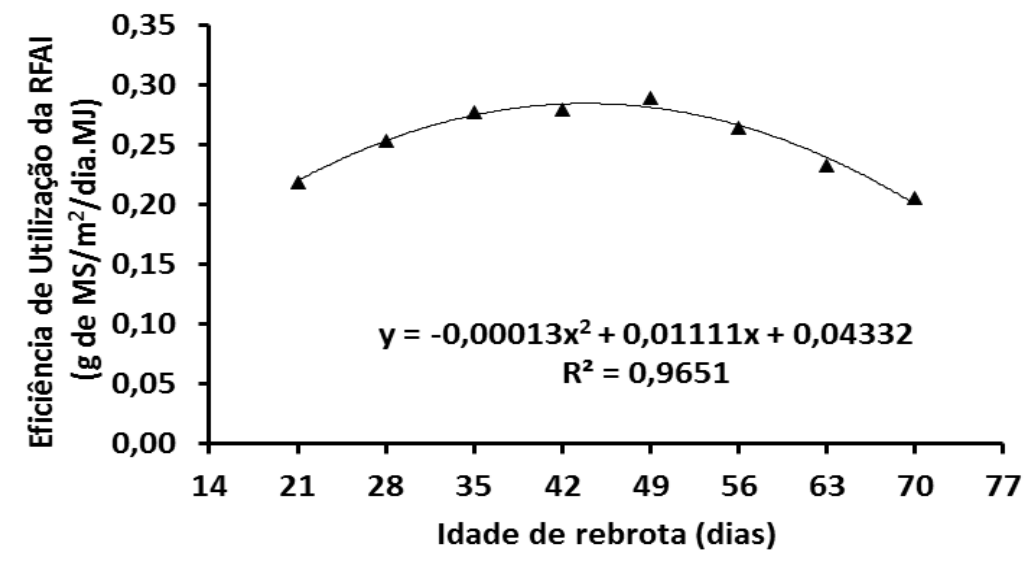

Fonte: Dados da pesquisa. 


\section{CONCLUSÃO}

A idade de rebrota afeta positivamente o rendimento de forragem, as taxas de crescimento, o índice de área foliar e a utilização da radiação fotossinteticamente ativa pela gramínea.

O período mais adequado para a utilização de pastagens de Trachypogon plumosus, durante o período chuvoso, situa-se entre 42 e 49 dias de rebrota, pois concilia produtividade de forragem e as taxas de crescimento com a maximização da eficiência de utilização da radiação incidente.

\section{REFERÊNCIAS}

BALDISSERA, T.C. Modelagem do crescimento de azevém anual sob pastejo. 2010 . $78 \mathrm{f}$. Dissertação (Mestrado em Agronomia) - UFPR, Curitiba, 2010. http://acervodigital.ufpr.br/handle/1884/24330

BARGER, N.N.et al. Nutrient limitation to primary productivity in a secondary savanna in Venezuela. Biotropica, Oxford, v.34, n.4, p.493-501, 2002. https://onlinelibrary.wiley.com/doi/abs/10.1111/j.1744$\underline{7429.2002 . t b 00569 . x}$

BARUCH, Z.; BILBAO, B. Effects of fire and defoliation on the life history of native and invader $\mathrm{C}_{4}$ grass in a Neotropical savanna. Oecologia, Amsterdam, v.119, p.510-520, 1999.

https://www.ncbi.nlm.nih.gov/pubmed/28307709

BARUCH, Z.; JACKSON, R.B. Responses of tropical native and invader $\mathrm{C}_{4}$ grasses to water stress, clipping and increased atmospheric $\mathrm{CO}_{2}$ concentration. Oecologia, Amsterdam, v.145, p.522-532, 2005. DOI 10.1007/s00442-005-0153-x

BARUCH, Z.; LUDLOW, M.M.; DAVIS, R. Photosynthetic responses of native and introduced $\mathrm{C}_{4}$ grasses from Venezuelan savannas. Oecologia, Amsterdam, v.67, n.3, p.388-393, 1985. https://link.springer.com/content/pdf/10.1007\%2FBF00384945.pdf

BONHOMME, R. Beware of comparing RUE values calculated from PAR vs. solar radiation or absorbed vs. intercepted radiation. Field Crops Research, Amsterdam, v.68, p.247-252, 2000.

http://dx.doi.org/10.1016/S0378-4290(00)00120-9

BORGES, B.M.M.N.et al. Relação entre o fluxo luminoso interceptado em diferentes épocas no índice de área foliar de diferentes forrageiras. Semina. Ciências Agrárias, Londrina, v.32, n.4, p.1589-1594, 2011. http://dx.doi.org/10.4025/actascianimsci.v30i1.3594

BRUM, M.S.et al. Produção animal e estrutura de uma pastagem natural submetida a diferentes sistemas de manejo. Acta Scientiarum. Animal Sciences, Maringá, v.30, n.1, p.9-16, 2008.

http://periodicos.uem.br/ojs/index.php/ActaSciAnimSci/article/view/3594

COOPER, J.P. Physiological and morphological advances for forage improvement. In:

INTERNATIONAL GRASSLAND CONGRESS, 14, Lexington, 1981. Proceedings... Lexington:

Westview Press, 1983. p.125-137.

COSTA, N. de L.; GIANLUPPI, V.; MORAES, A. Morfogênese da rebrota de Axonopus aureus, durante o período seco, em cerrado de Roraima. Revista Científica de Produção Animal, Teresina, v.16, n.1, p.1-9, 2014. http://dx.doi.org/10.15528/2176-4158/rcpa.v16n1p1-9

COSTA, N. de L.et al. Produtividade de forragem e morfogênese de Trachypogon plumosus nos cerrados de Roraima. Amazônia Ciência \& Desenvolvimento, Belém, v.8, n.16, p.65-80, 2013.

http://www.bancoamazonia.com.br/images/arquivos/institucional/biblioteca/revista amazonia/edicao16/R 16 Produtividade de Forragem .pdf 
COSTA, N. de L.et al. Acúmulo de forragem e eficiência de utilização da radiação em pastagens de Axonopus aureus, durante o período seco, nos cerrados de Roraima. Revista Agroambiente On-line, Boa Vista, v.5, n.2, p.143-147, 2011. http://dx.doi.org/10.18227/1982-8470ragro.v5i2.510

DU, X.et al. Effect of cropping system on radiation use efficiency in double-cropped wheat-cotton. Field Crops Research, Amsterdam, v.170, p.21-31, 2015. http://dx.doi.org/10.1016/j.fcr.2014.09.013

FONSECA, E.L.; SILVEIRA, V.C.P.; SALOMONI, E. Eficiência de conversão da radiação fotossinteticamente ativa incidente em área da vegetação campestre natural no bioma Campos Sulinos do Brasil. Ciência Rural, Santa Maria, v.36, n.2, p.656-659, 2006. http://www.redalyc.org/pdf/331/33136247.pdf

GIANLUPPI, D.; GIANLUPPI, V.; SMIDERLE, O. Produção de pastagens no cerrado de Roraima. Boa Vista: Embrapa Roraima, 2001. 4p. (Comunicado Técnico, 14).

GOMIDE, C.A.M.et al. Fotossíntese, reservas orgânicas e rebrota do Capim-Mombaça (Panicum maximum Jacq.) sob diferentes intensidades de desfolha do perfilho principal. Revista Brasileira de Zootecnia, Viçosa, v.31, n.6, p.2165-2175, 2002. http://www.scielo.br/pdf/rbz/v31n6/a03v31n6

HUMPHREYS, L.R. Tropical pasture utilization. Cambridge: Cambridge University Press, 1991, 206p.

LEMAIRE, G. Ecophysiological of grasslands: Dynamics aspects of forage plant population in grazed swards. In: INTERNATIONAL GRASSLAND CONGRESS, 19., 2001, São Paulo, Proceedings... São Paulo: ESALQ, 2001, p.29-37. http://www.internationalgrasslands.org/files/igc/publications/2001/tema1$\underline{1 . p d f}$

LEMAIRE, G.; AGNUSDEI, M. Leaf tissue turnover and efficiency of herbage utilization. In: LEMAIRE, G.et al. Grassland ecophysiology and grazing ecology. London: CAB International, 2000. p.265-288. http://www.cabi.org/cabebooks/FullTextPDF/2000/20003019261.pdf

LEMAIRE, G.; HODGSON, J.; CHABBI, A. Grassland productivity and ecosystem services. Wallingford: CABI, 2011. 287p. http://dx.doi.org/10.1079/9781845938093.0000

MATA, D.; MORENO, E.; ROJAS, N.R. Efecto de la edad sobre la composición química del Trachypogon spp. en una sabana del Sureste del Estado Guarico. Zootecnia Tropical, Caracas, v.3, n.1, p. 29-48, 1985.

https://www.researchgate.net/publication/259042626_Effect_of_age_on_the_chemical_composition_of_T rachypogon_spp_in_a_savanna_in_the_southeast_of_Guarico_state_Venezuela_Zootecnia_Tropical_3_1_ and 2 29-45

MOCHIUTTI, S.; SOUZA FILHO, A.P.; MEIRELLES, P.R.L. Efeitos da queima sobre a produção total e rendimento das espécies em uma pastagem nativa de cerrado do Amapá. Macapá: Embrapa Amapá, 2000. 14.p. (Documentos, 37).

http://ainfo.cnptia.embrapa.br/digital/bitstream/item/96300/1/CPAF-AP-2001-Queima-Cerrado.pdf

NABINGER, C.; CARVALHO, P.C.F. Ecofisiología de sistemas pastoriles: aplicaciones para su sustentabilidad. Agrociencia, Buenos Aires, v.3, p.18-27, 2009.

http://www.fagro.edu.uy/agrociencia/index.php/directorio/article/view/232/169

PARSONS, A.J.; CHAPMAN, D.F. The principles of pasture growth and utilization. In: HOPKINS, A. (Ed.). Grass, its production and utilization. London: Blackwell Science, p.31-89, 2000.

PEDREIRA, B.C.; PEDREIRA, C.G.S. Fotossíntese foliar do capim-xaraés (Brachiaria brizantha (A.Rich.) Stapf. cv Xaraés e modelagem da assimilação potencial de dosséis sob estratégias de pastejo rotativo. Revista Brasileira de Zootecnia, Viçosa, v.36, p.773-779, 2007.

http://dx.doi.org/10.1590/S1516-35982007000400004 
RIPPSTEIN, G.; ESCOBAR, G.; MOTTA, F. Agroecologia y biodiversidad de los Llanos Orientales de Colombia. Cali, Colombia: CIAT, 2001. 302 p.

SCHÖFFEL, E.R.; VOLPE, C.A. Eficiência de conversão da radiação fotossinteticamente ativa interceptada pela soja para produção de fitomassa. Revista Brasileira de Agrometeorologia, Santa Maria, n.2, v.9, p.241-249, 2001. http://coral.ufsm.br/rba/p24192.html

SHEEHY, J.E.; COOPER, J.P. Light interception, photosynthetic activity, and crop growth rate in canopies of six temperate forage grasses. Journal of Applied Ecology, Oxford, v.10, p.239-250, 1973. https://www.jstor.org/stable/2404727

SHIBLES, R.M.; WEBER, C.R. Interception of solar radiation and dry matter production by various soybean planting patterns. Crop Science, Madison, v.6, p.55-59, 1966.

http://dx.doi.org/10.2135/cropsci1966.0011183X000600010017x

SHIBLES, R.M.; WEBER, C.R. Leaf area, solar radiation interception, and dry matter production by various soybean planting patterns. Crop Science, Madison, v.6, p.575-577, 1965.

https://dl.sciencesocieties.org/publications/cs/abstracts/5/6/CS0050060575

SILVA JÚNIOR, L.C.; SILVA, W.J.; BISINOTTO, F.F. Efeito da radiação fotossinteticamente ativa no crescimento e desenvolvimento de gramíneas forrageiras. Belo Horizonte: EPAMIG, 2009, 4p. http://dx.doi.org/10.2135/cropsci1966.0011183X000600010017x

SIVAKUMAR, M.V.K.; VIRMANI, S.M. Crop productivity in relation to interception of photosynthetically active radiation. Agricultural and Forest Meteorology, Oxford, v.31, n.1, p.131-141, 1984. http://dx.doi.org/10.1016/0168-1923(84)90015-7.

TEJOS, R. Pastos nativos de sabanas inundables: caracterización y manejo. Barquisimeto, Venezuela: Megagraf, 2002. 111p. http://www.avpa.ula.ve/docuPDFs/libros_online/pastos_nativos/contraportada.pdf 